\title{
DATA EXCHANGE PROTOCOL IN REPSAIL
}

\begin{abstract}
Article presents implantation and theoretical considerations of data exchange protocol developed for the RepSail project, where main objective was design and building innovative hybrid yacht. One of problems during the design process was improper functioning of data exchange protocols that were available in the commercially available devices to mention navigation purpose NMEA183 or 2000 as well as automation dedicated ones (CAN and similar). Author shows the basis of the dedicated format of exchange for in board devices.
\end{abstract}

\section{Keywords:}

hybrid yacht, protocol, data exchange.

\section{INTRODUCTION}

With REP-SAIL (Renewable Energy Powered Hybrid Innovative Sailing Yacht) Project, it is aimed that the energy needed for propulsion systems and living area in a vessel will be provided by directly or indirectly without using fossil fuels except for emergency situations. All works that are going to be performed in project scope is planned for development current systems on vessels and integration to system. General system structure will be revised because of the changes in components in order to maximize efficiency of energy transformation. All development activities that both two universities and two industrial companies are going to work in project scope, will be performed parallel to each other. With leadership of MILPER, Maritime University of Szczecin (MUS), Warsaw University of Technology (WUT), Autocomp Management Sp. z o.o. (ACM) will create a yacht concept only using biological material based composites, 
will expose zero emission and will use different types of renewable energy resources. Project RepSail that has been co financed by ERANet Transport (under NCBIR Agency).

In project scope following innovative implementation has been included:

- resistant to open sea conditions, durable, integrate able on deck of vessel solar panels;

- venture turbines that able to use any low powered wind coming from any point of the vessel and a wind generator to produce electric;

- energy producing water turbines using flows under the vessel while sailing;

- electrical propulsion systems that are using the energy produced on vessel in order to move the vessel efficiently;

- lithium polymer batteries in order to store the electric energy with minimum loss for a long period properly under conditions of sea;

- energy efficiency increasing management system for transferring the energy stored or produced to needed regions on vessel;

- variable fin keeled vessel design in order to provide maximum efficiency for renewable energy components and lowering needed energy, works are going to be performed.

One of the most demanding issues was to create efficient and safe data exchange system. Nowadays the information must be presented in the manner that will allow to:

- safely perform maneuver;

- perform it with the proper timing;

- avoid overriding of information.

This issue has found several scientific attempts where beginning for maritime world has been addressed in: [Smith, Mosier, 1986; Rothblum, Carvalhais, 1996]. Consideration over the display and parametric optimization of information has been addressed in [Gucma, Pietrzykowski, 2009].

In the Rep Sail yacht CAN (or NMEA 0183, CAN J1939, TCP/IP, etc.) bus network has been implemented to monitor and control of the yacht. Where it was applicable M2M (machine to machine) systems were used as standardized ones (NMEA 2k). Following systems (M2M) can, not be implemented to the network where important data must be transmitted and properly used. This issue at merchant solution has been widely presented since ARPA was born, and large amount of data flows inside the ship navigation systems. Most common modern work has its representation in [Baronti et al., 2009] Authors presents protocol as a whole 
concept for transmission and interpretation (understanding) of data represented inside the system. Basic concept of the network implemented at RepSail yacht is presented at Figure 1. This is only navigational layer with the human machine interfaces (H2M/M2H human to machine concept). Most of devices in this layer were Simrad/Kongsberg produced devices.

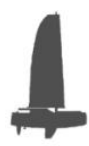

Rep Sail

Navigation equipment layout

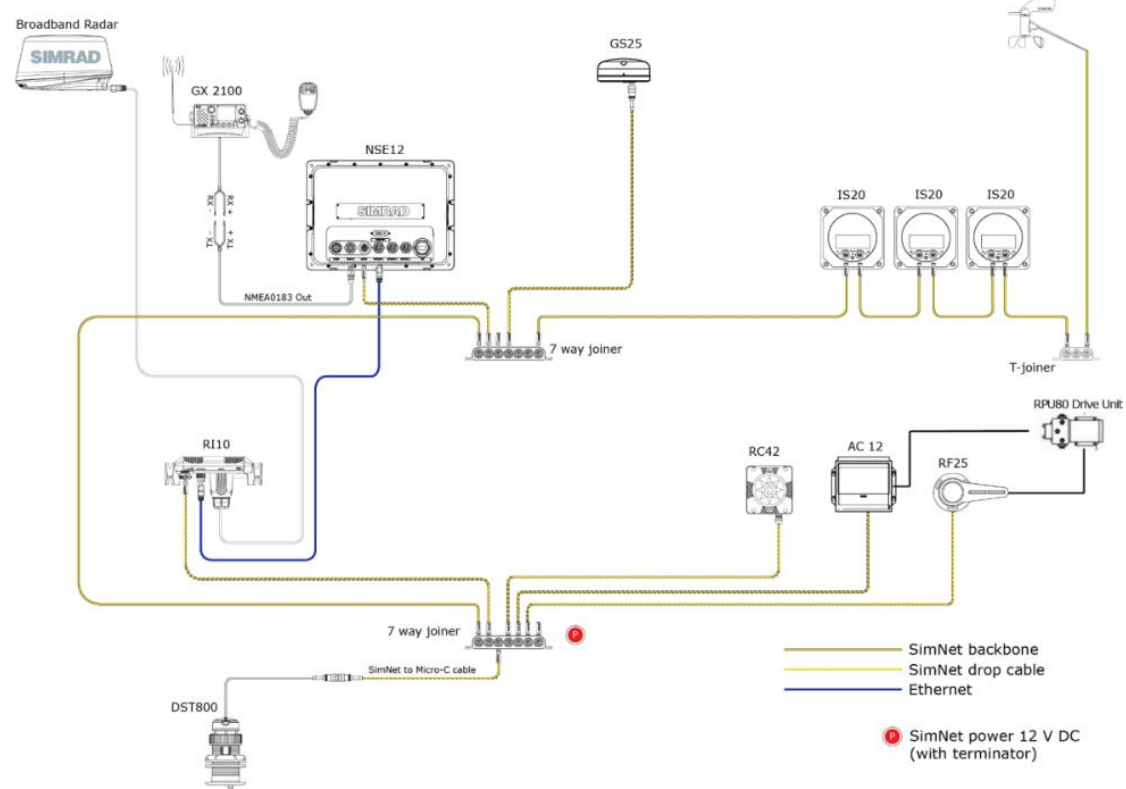

Fig. 1. Network of navigation devices in RepSail yacht

[https://digitalyacht.net/connecting-our-new-aisnode-receiver-to-a-simrad-network/]

One of largest issues is proper determination of amount of information and its proper representation in the protocol that will be utilized. In the article some theoretical assumptions will be presented.

\section{NAVIGATION INFORMATION OPTIMIZATION}

Optimization in general means can be defined as a science of choosing methods for best fit action related to human activity (in the economy, technology 
or social means). Mathematical representation is related to choosing minima (usually and in general always local minima) of given function. This action is called optimization nevertheless if we are searching for local maxima or minimas.

Navigational information optimization is defined as problem of choosing set of information and its state [Gucma, Pietrzykowski, 2009]. So not only amount is a cut set value but its imagination either. This amount of information must ensure proper state of safety of navigation itself whenever high economical efficiency must be another cut set for optimization. Some of these aspects has been presented in: [Gucma, 2009] and followed in [Gucma, 2016].

Gaining such stated (and simplified) assumption, following mathematical model must be defined:

- target function (or functions) is known — defined as mathematical expression of optimization criteria;

- cut set of decision making variables and other parameters defining its construct;

- boundary conditions [Ostwald, 2005].

Having protocol of data exchange as a main purpose, for optimal and most cost effective data communication system in RepSail following factors has been considered:

- size of system;

- accuracy of exchanged data;

- reliability of whole data exchange.

Inside local network for complex RepSail data exchange system its necessary to define cut sets of strict rules of data exchange (steps) for data transmission to be performed properly. Thus such protocol can ensure safe and efficient navigation, keeping operator in mind.

\section{TOPOLOGY OF SYSTEM}

Creation of topology describing the method of data transmitted throughout the physical devices is connected with the mathematical programming. This technique is related with mathematical theories development along with the numerical programming. For this area searching of extrema (minima) of variables inside function is seeked. Target function is function for which we search for minimas. 
Defining target function $Z=Z(X)$ and target functions $f=f(X)$, where $X=\left(x_{1}, x_{2}, \ldots, x_{n}\right)$, mathematical programming is divided to:

- linear programming tasks target function $Z=Z(X)$ and boundry function $f=f(X)$ are linear (first order);

- non linear programming where target function $Z=Z(X)$ or boundry function $f=f(X)$ are non linear.

Where dynamical programming is assumed, target function $Z=Z(X)$ and boundry function $f=f(X)$ varies in time, decision thus is solved as a multistep and target function $Z=Z(X)$ can become [Andrilli, Hecker, 2016]:

- additive

$$
Z(X)=\sum_{i=1}^{n} z_{i}\left(x_{i}\right)=z_{1}\left(x_{1}\right)+z_{2}\left(x_{2}\right)+\ldots+z_{n}\left(x_{n}\right)
$$

or

- multiplicative

$$
Z(X)=\prod_{i=1}^{n} z_{i}\left(x_{i}\right)=z_{1}\left(x_{1}\right) \cdot z_{2}\left(x_{2}\right) \cdot \ldots \cdot z_{n}\left(x_{n}\right) .
$$

Inside the RepSail network it has been established that both additive and multiplicative cases of mathematical programming can occur.

\section{PROTOCOL DEVELOPMENT}

Design of the mathematical protocol consists of following steps performed before its final shape can be translated to machine language:

1. Construct of mathematical model determination of unknowns.

2. Target function design.

3. Boundary functions applications.

AD. 1. Unknowns determination where set of unknows $x=\left(x_{1}, x_{2}, \ldots, x_{n}\right)$ - i.e. operations that allows to modify model in order to improve of protocol functioning. Unknowns here are reffered to so called task plan.

AD. 2. Target function - allows us to choose proper variants form defined limited set of available results. In real world this sets are tend to be unlimited but for our assumptions we can treat them as limited factor. Value of target function (its solution) in extremum (minima) it shows best fit to solution. 
AD. 3. boundary functions are overlaid on the unknown values.

By definition, finding the proper task of mathematical programming is finding the task plan: $x=\left(x_{1}, x_{2}, \ldots, x_{n}\right)$, for which target function $Z$ will achieve its extrema (min or max) $Z=z\left(x_{1}, x_{2}, \ldots, x_{j}, \ldots, x_{n}\right)$, for boundaries $f_{i}\left(x_{1}, x_{2}, \ldots, x_{j}\right.$, $\left.\ldots, x_{n}\right)\{\leq$ or $=$ or $\geq\} b_{i}, i=1,2, \ldots, m$.

Variables that are used to creation of protocol shall fulfill $x_{j} \geq 0(j=1,2, \ldots, k)$, or in most cases it shall be at least with the integer set number set $\left(x_{j} \in Z\right.$, where $Z$ - integers $(j=1,2, \ldots, k))$.

We can assume navigational devices $P_{1}, P_{2}, \ldots P_{j}, \ldots P_{n}$. (GNSS receiver, ECDIS, Radar, AIS receiver, sonar, autopilot etc.), that transmits certain information from following obligator sets:

- information over the area (depth contours, proximity of navigation obstructions, navigational marks);

- information of the position of vessel at area;

- prediction information for own vessel with given time horizon.

Given vessel carries $j$-th navigation devices that stores and transmits $a_{i j}$ amount of information's $i$-th. In the given amount of time it will be necessary to achieve not less than $b_{i}$ parts of $i$-th information. We can also include cost of device $c_{i}$. Here we can assume the optimal set of $i$-th devices with function of its cost and assume the plan of task as a: $\boldsymbol{x}=\left(x_{1}, x_{2}, \ldots, x_{n}\right)$.

Cost effective model can be presented as [Ostwald, 2005]:

$$
\min Z=c_{1} \cdot x_{1}+c_{2} \cdot x_{2}+\ldots+c_{n} \cdot x_{n}=\sum_{j=1}^{n} c_{j} \cdot x_{j}
$$

for boundries

$$
a_{i 1} \cdot x_{1}+a_{i 2} \cdot x_{2}+\ldots+a_{i n} \cdot x_{n} \geq b_{j} \text { or } \sum_{j=1}^{n} a_{i j} \cdot x_{j} \geq b_{i}(i=1,2, \ldots, m),
$$

where:

$x_{j} \geq 0, j=1,2, \ldots, n$.

Then whole task can be represented as a linear progrmming as:

$$
\max (\min ) Z=c_{1} \cdot x_{1}+c_{2} \cdot x_{2}+\ldots+c_{n} \cdot x_{n}=\sum_{j=1}^{n} c_{j} \cdot x_{j} \quad \text { - target function }
$$


with constrains:

$$
\begin{aligned}
& a_{i 1} \cdot x_{1}+a_{i 2} \cdot x_{2}+\ldots+a_{i n} \cdot x_{n} \leq b_{j} \text { or } \sum_{j=1}^{n} a_{i j} \cdot x_{j} \leq b_{i},\left(i=1,2, \ldots, m_{1}\right) \\
& a_{i 1} \cdot x_{1}+a_{i 2} \cdot x_{2}+\ldots+a_{i n} \cdot x_{n}=b_{j} \text { or } \sum_{j=1}^{n} a_{i j} \cdot x_{j}=b_{i},\left(i=1,2, \ldots, m_{1}\right) \\
& a_{i 1} \cdot x_{1}+a_{i 2} \cdot x_{2}+\ldots+a_{i n} \cdot x_{n} \geq b_{j} \text { or } \sum_{j=1}^{n} a_{i j} \cdot x_{j} \geq b_{i},\left(i=1,2, \ldots, m_{1}\right),
\end{aligned}
$$

where:

$x_{j} \geq 0, j=1,2, \ldots, n_{1}$,

$x_{j}$ - any value $\left(j=n_{1}+1, n_{1}+2, \ldots, n\right)$,

$c_{j}, a_{i j}, b_{i}$ - real values,

$\boldsymbol{x}=\left(x_{1}, \ldots, x_{n}\right)-$ task plan.

\section{FUTURE WORK}

Following to the presented above will be deign of the protocol according to state of the art knowledge over the needs of navigator. Assuming that we deliver the product of final navigation system to anon professional skipper of leisure boat we need to address following:

- readability of the information its visualization;

- amount of information not to overload human;

- level of data refreshing.

Similar problem has been addressed in [Smith, Mosier, 1986] for the design of aircraft interfaces. Problem of protocol optimization was treated there as a black box concept where only outputs and inputs were seen. Such guidelines are both necessary and generating another problem — if they will be accepted by the whole world of manufacturers.

In the RepSail project following data has been defined as a one to be gathered:

1. Engine and battery data: electric engines are utilized here with the direct control. DC motors are controlled by the proprietary drivers communicated by the CAN (SAE J-1939) network to engine ECU and battery driver. 
2. Navigation system: here the NMEA protocol with its NMEA 2000 implementation is utilized. Data transferred in this sub-system are very complex and multidimensional. Data overlaps each other (for example: ARPA data wraps data from AIS but coherence is not always obvious). Dedicated protocol must encapsulated whole messages and after filtering must be presented to user or another subsystem.

3. Steering subsystem: here dedicated protocol must be utilized to control yacht in means of charge current, solar panel status, wind and hydroturbines status as well as other charging and discharging sources and drains.

4. On-board equipment: many drains of electrical energy is managed in the priority (where leas significant drains can be switched off when power level is not sufficient).

\section{SUMMARY}

Article presents idea and theoretical implementation of the protocol for RepSail innovative hybrid powered yacht. Optimization functions has been presented for the further development and setting up practice. It has been defined how the future work will be handled and implemented in real system.

\section{REFERENCES}

[1] Andrilli S. F., Hecker D., Elementary linear algebra, Elsevier Academic Press, Amsterdam — Boston 2016.

[2] Baronti F., Marraccini E., Roncella R., Saletti R., Manni G., Palama G., Multi-sensor multi-protocol acquisition system for luxury-yacht production test and characterization, IEEE, 2009, pp. 1-6, DOI: 10.1109/ICSCS.2009.5414188.

[3] Gucma M., Models of maritime safety for development of navigation support systems, 'Archives of Transport', 2016, 37, pp. 31-41, DOI: 10.5604/08669546.1203201.

[4] Gucma M., The method of the selection of the navigational information in decision support pilotage systems [in Polish], Publ. Warsaw University of Technology, Warszawa 2009.

[5] Gucma M., Pietrzykowski Z., Optimization of the navigation information in electronic map systems [in Polish], 'Logistyka', 2009, No. 4, CD.

[6] Ostwald M., Bases of construction optimization [in Polish], Publ. Poznań Univerity of Technology, Poznań 2005. 
[7] Rothblum A. M., Carvalhais A. B., Maritime Applications of Human Factors Test and Evaluation, [in:] Handbook of Human Factors Testing and Evaluation, T. G. O'Brien and S. G. Charlton, CRC Press, Mahwah, NJ, Lawrence Erlbaum Assoc., 1996.

[8] Smith S. L., Mosier J. N., Guidelines for designing user interface software (No. (ESD-TR-86-278)), Hanscom Air Force Base, MA: Electronic Systems Division, AFSC, United Sates Air Force, MA, USA, 1986.

Received October 2016

Reviewed November 2017

Published 08.12.2017

\section{MACIEJ GUCMA}

Maritime University of Szczecin

Wały Chrobrego 1-2 Str., 70-500 Szczecin, Poland

e-mail:m.gucma@am.szczecin.pl

\section{PAULINA HATLAS}

Maritime University of Szczecin

Wały Chrobrego 1-2 Str., 70-500 Szczecin, Poland

e-mail: p.hatlas@am.szczecin.pl

\section{STRESZCZENIE}

$\mathrm{W}$ artykule przedstawiono podstawy teoretyczne dla budowy protokołu wymiany danych opracowanego w ramach projektu RepSail. Jednym z podstawowych problemów, jaki napotkano podczas realizacji, było niewłaściwe działanie protokołów dostępnych w komercyjnych urządzeniach nawigacyjnych jak NMEA0183 czy 2000 lub w układach automatyki jak CAN. 